\title{
Advanced Supervisory Control Plan with Power Saving Strategy for Demand Side Load
}

\author{
Meer Shadman Shafkat Tanjim, Md. Abdur Rahman, Ashrafun Nushra Oishi
}

\begin{abstract}
Demand Side Power Management is getting crucial to control the gradual rise of electrical power usage day-by-day. Though, the spread of power saving devices is a huge success throughout the world, yet the demand side power management system has to be more efficient and controlled. Here, a unique power saving strategy was established by intranet based Advanced Supervisory Control system. The core system consists of XPSU, XCU, PBU, DS and ASC. Planning of this system has been done not only to solve the above-mentioned criteria but also to reduce huge electricity demand from national grid. To reduce the National Grid pressure, full utilization of renewable energy grid output is ensured in this strategy. By this control plan, maximum 31.9\% of the instantaneous power has been saved by $11.11 \%$ of system-end ASC switching. A new idea, Electrical Mapping is also introduced for every different load section; by which the load behavior and power consumption history of our different load site area can be understood.
\end{abstract}

Keywords-Electrical Mapping, Demand Side SCADA, Power Saving Technology, Advanced Supervisory Control (ASC) Plan, ASC of Demand Side Load (ASC-DSL), XPSU, XCU, PBU, DS, Minimum usage of National Grid Power, Renewable Energy Grid Priority, Simplified Control Plan, Demand Side Data.

\section{INTRODUCTION}

Demand side load management became worthy to research to subdue power system faults, loss and system problems. Along with unbalanced load related problem, more small issues had become a fact when energy audits were done in several places [1]. Considering the facts, SCADA system has changed the low voltage side distribution system automation criteria to new level [2]. From then SCADA system become popular for not only distribution side but also entered the demand side sectors. But on demand side sector, SCADA is not maintaining the intelligence that it should go through [3-4]. Researcher tried some technique for data acquisition [5]. Even they are one

\section{Meer Shadman Shafkat Tanjim}

Graduate Student

American International University-Bangladesh

Dhaka, Bangladesh

meer.tanjim@yahoo.com

\section{Md. Abdur Rahman}

Professor and Associate Dean

Faculty of Engineering

American International University-Bangladesh

Dhaka, Bangladesh

arahman@aiub.edu

\section{Ashrafun Nushra Oishi}

Graduate Student

American International University-Bangladesh

Dhaka, Bangladesh

ashrafun_nushra@yahoo.com step forward for the portability behavior with accuracy but always missing the system portability or installation ease factors [6-7]. From household to commercial sites, intelligent demand side management has been working maximum by load shifting and balancing inductive load characteristics. Some of them faces run-time error [8], decision clash error and some of them maximize the bill for making the management look so effective for load handling [9]. Still Somehow, stable demand side management is under several algorithm and action to perform its high duty [10-16]. Renewable energy necessity is also growing day-by-day [17]. Sustainability of the multi-grid approach should be take care of too [18-23].

In this research, Advanced Supervisory Control for Demand Side Load (ASC-DSL) System is designed not only for maximizing the power saving criteria without hampering the load schedule, but also for minimizing the national power grid pressure. Electrical Mapping theory is newly introduced on this research, which will visualize the load behavior and the whole characteristics. This Electrical Mapping will also help ASC to analyze on the go.

\section{STRATEGY OF ASC FOR DEMAND SIDE LOAD}

The strategy is designed in a way that all the technologies are bind with a core, by which they are controlled. Moreover, a smart data acquisition system is designed to collect the data to the Data Server. The data collection from the power line in a portable way has given the strategy a new dimension for the control plan. Before entering to the concept, the initial system criteria should be mentioned as -

$\begin{array}{lll}\text { - } & \text { XPSU } & \text { (X Power Saving Unit) } \\ \text { - } & \text { XCU } & \text { (X Control Unit) } \\ \text { - } & \text { PBU } & \text { (Power Bypass Unit) } \\ \text { - } & \text { DS } & \text { (Data Server) } \\ \text { - } & \text { ASC } & \text { (Advanced Supervisory Control) }\end{array}$

These five units will initially build up the Power Saving Strategy, where it will serve for maximum power usage but with as much as less cost it appears. To reduce National Grid pressure, Maximum usage of Renewable Energy Grid is encouraged in this system.

XPSU will be installed on the room or any load area where it will monitor usage and shut down the power input of specific load if the usage is not required. Suppose, for a classroom when students get out from the room, we do not have any reason to power up the room itself. Even if one student is present, we do not need to light up the whole room instead of lighting few portions of the room for safety.

$\mathrm{XCU}$ will send the power data from the sub-distribution board's power line and wait for the ASC instruction to switch the circuit breaker for different purpose. 
To reduce National Grid pressure in power consumption facts, PBU will serve a major activity flow with the help of ASC intelligence. It will maximize the renewable energy grid's power inlet and minimize the national grid's power inlet according to the instantaneous Demand Data.

Collecting all required data from the system, Data Server (DS) will help to arrange Electrical Mapping Data by which ASC will decide further important decision for future Power Saving plan.

ASC is the core unit of the plan. All the major units are connected to it in an intranet-based communication system. ASC will receive data and send instruction to the units to perform several tasks. Major portion of the tasks are designed for automation. But this automation will be inspired by some predefined instructions from human. Suppose, if the instruction is given that the user needs to buckle up the bill within 500 dollar instead of 600 dollar, then it will try to handle the load based on priority level and reduce the power usage that helps to reach the expected cost defined by user, without neglecting the essential usage. The entire communication is based on intranet. The reason behind it, is to avoid hassle in secured operation.

\section{MODELING OF DEMAND SIDE ASC PLAN}

To implement the Power Saving Strategy by means of ASC, the modeling of the system was arranged in a way that both user and service provider can have proper advantage out of it.

\section{A. Whole ASC Model:}

On the entire model, the five major units are placed in different place. From them, XCU, PBU and ASC are connected together to an intranet connection. XPSU should be fully automated as installation hardware and process are different for different load environment. However, it can be inspired by user defined instruction if needed. For that, it will also be needed to connect to the network.

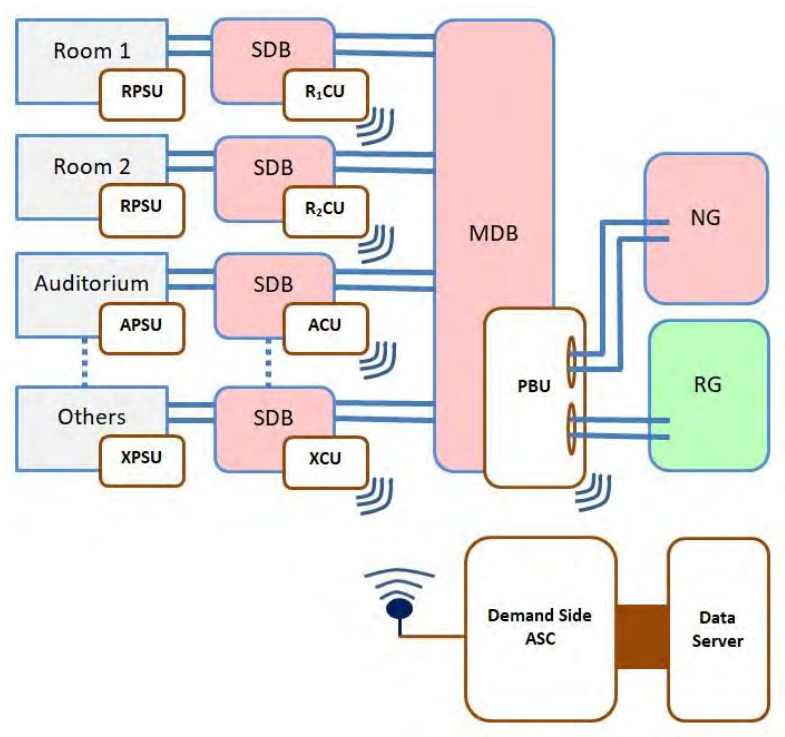

Fig. 1: Advanced Supervisory Control (ASC) Plan
XPSU is named under environment. It will be named as RPSU for Room environment, APSU for Auditorium Environment, CPSU for Conference Hall environment and so on. On each SDB (Sub Distribution Board) of different area, XCU is installed and the naming of that XCU will be named as XPSU. For multi-purpose use of same XPSU, number subscript is attached like $\mathrm{R}_{1} \mathrm{CU}, \mathrm{R}_{2} \mathrm{CU}$.

PBU is installed on MDB (Main Distribution Board). NG (National Grid) inlet and RG (Renewable energy Grid) inlet are attached to the PBU first. PBU performs its task by ASC instructions.

Demand Side ASC unit will handle all these units and stores data to DS. DS should be designed in a way that the specific data is stored in specific criteria by which ASC can map the electrical mapping database. These E.M. (Electrical Mapping) Data will be shown in front of every XCU unit with a display and on the ASC Database screen also.

\section{B. Power Bypass Unit (PBU) Model:}

According to the instruction of ASC unit, Microcontroller will regulate the NG/RG switch to let the power in to the MDB Bus-bar. The entire calculation will be done by ASC itself. PBU will just obey ASC decision.

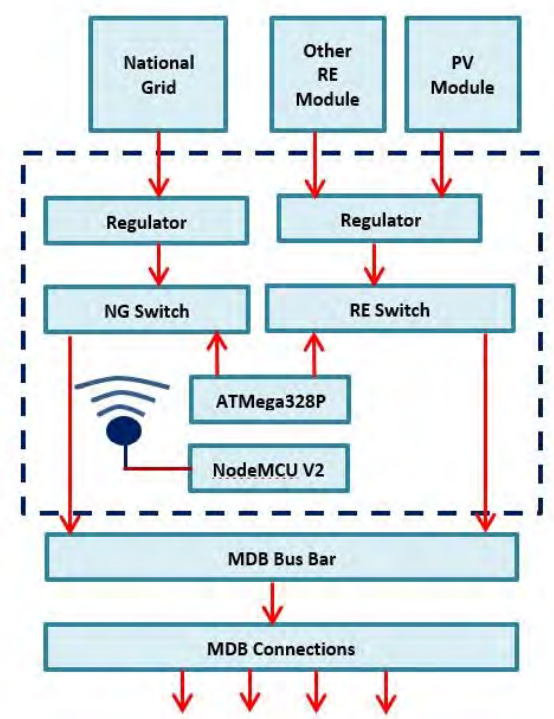

Fig. 2: PBU Model

\section{Room/Other Usage Control Unit (RCU/XCU) Model:}

On each SDB, the power line for each CB (Circuit breaker) will consist of Hall effect sensor, Microcontroller, CB Switcher/Relay, Wi-fi data transfer module.

Hall effect sensor will take the analog input for power calculation in microcontroller. Microcontroller will send the instantaneous accurate data to ASC. ASC will sense it and will order the microcontroller if $\mathrm{CB}$ switcher will switch on or off the $\mathrm{CB}$. 


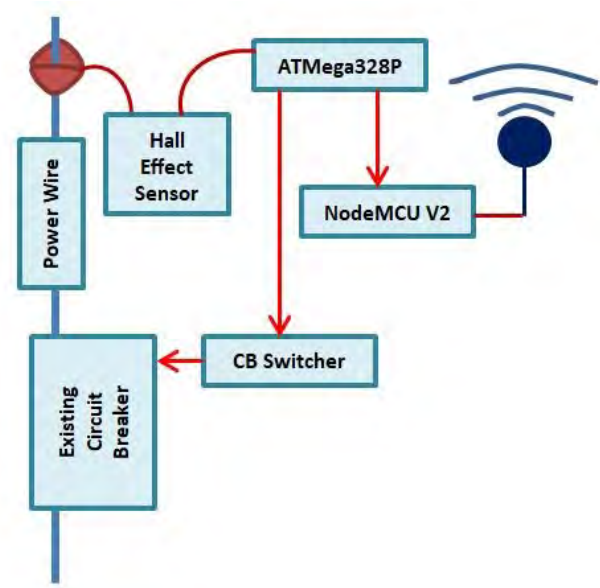

Fig. 3: XCU Model

\section{ALGORITHMIC APPROACH FOR DIFFERENT UNITS}

The Algorithms mentioned on different section, give the system operation nature and stability by which we can maintain the level.

\section{A. Room/Other Usage Power Saving Unit (RPSU/XPSU):}

Initial XPSU will consist of two sensors. One sensor will Count the human presence and other will count the human absence comparing to the presence. Sensing the first entrance, enables the power up. While, sensing the last absence, disables the power up. And after sensing the last entrance, it restarts the entrance count.

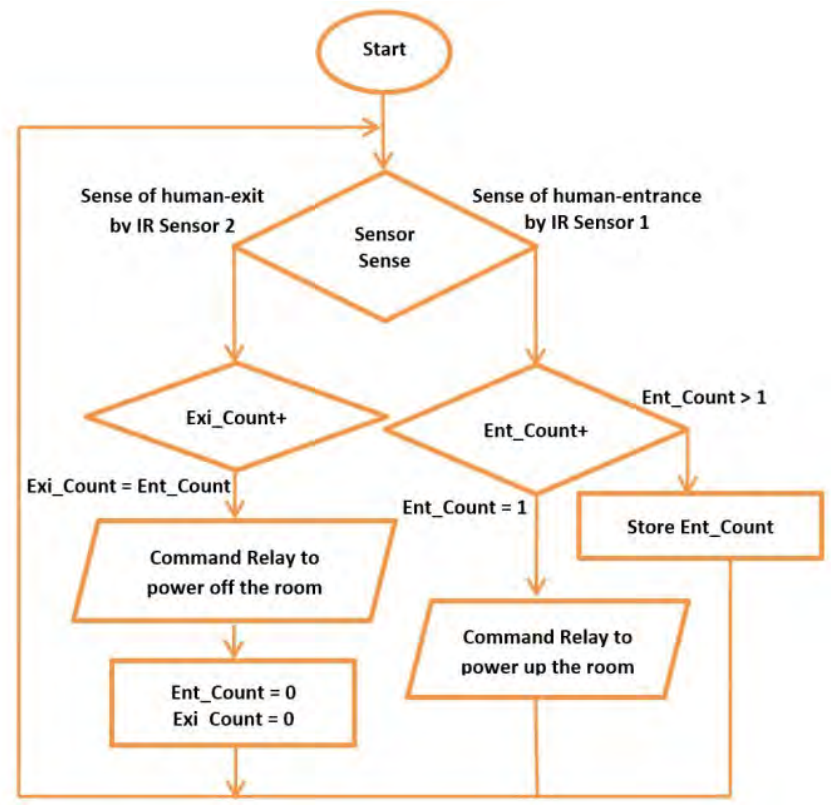

Fig. 4: XPSU Working Sequence

\section{B. Power Bypass Unit (PBU):}

Power Bypass Unit will minimize the National Grid Pressure by assuring maximum utilization of Renewable Energy (RE) Grid Power without hampering the Demand.

PBU will work with the information of Data Server and ASC instruction. First it will call necessary instantaneous data from Data Server (DS). This instantaneous data can be of the statistical data of previous year of that date, day and season for best assumption of Power Consumption. And ASC will also balance or override the action, if there is any user defined Power Consumption suggestion.

After calling the data from DS, ASC will analyze the Instantaneous Maximum Demand $\left(\mathrm{I}_{n} \mathrm{M}_{\mathrm{ax}} \mathrm{D}\right)$. If $\mathrm{I}_{n} \mathrm{M}_{\mathrm{ax}} \mathrm{D}$ becomes greater than Maximum Input from Renewable Energy ( $\left.M_{a x} I R E\right)$, then it will set the Minimum Input from National Grid $\left(M_{\text {in }} I N G\right)$ equals to the subtract value of the $I_{n-}$ $M_{\mathrm{ax}} \mathrm{D}$ from $\mathrm{M}_{\mathrm{ax}} \mathrm{IRE}$. This will be the Minimum Power Consumption from National Power Grid. Moreover, There will be an Additional Input from National Grid (AING), databased from variable consumption data for standby purpose.

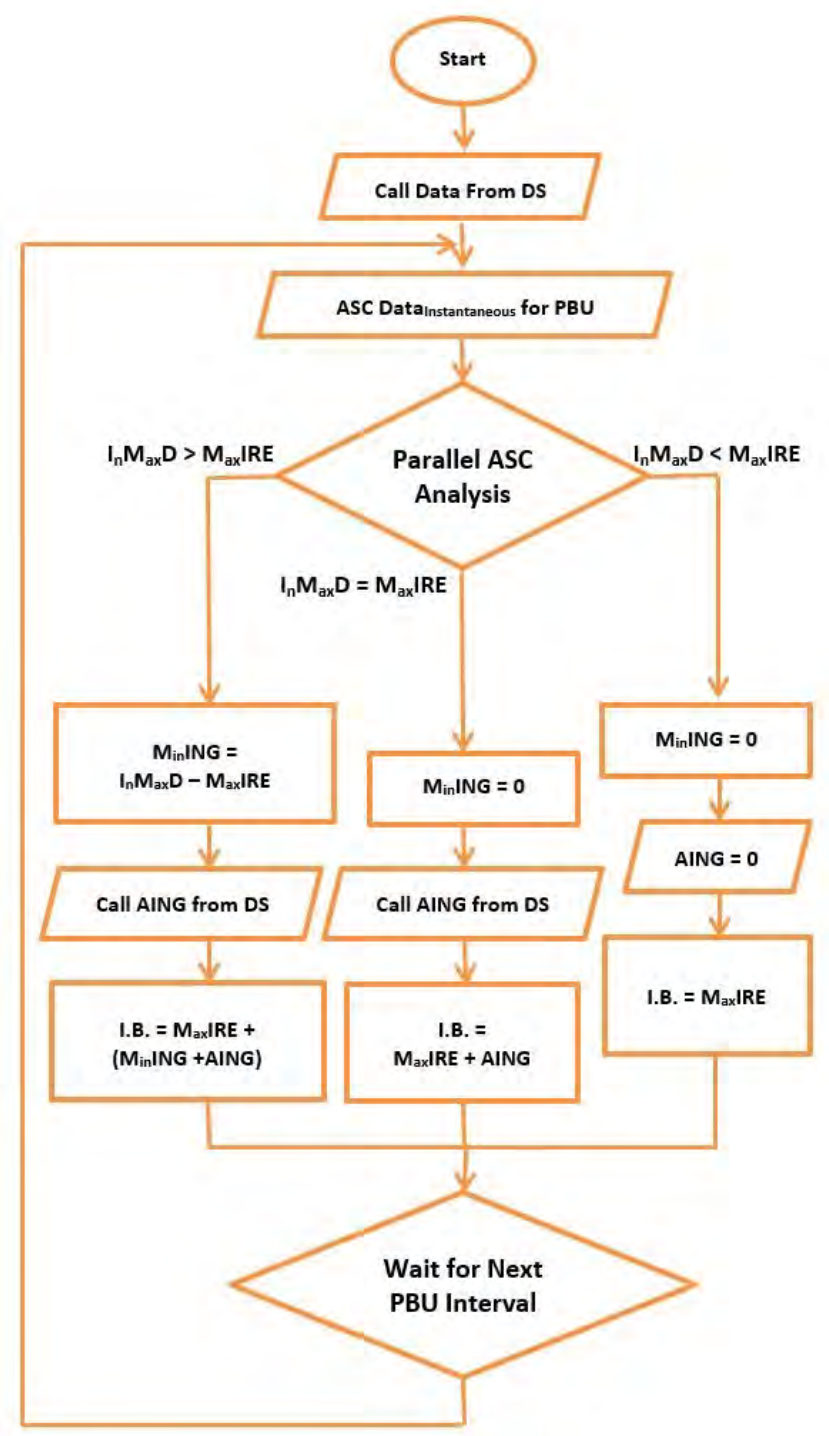

Fig. 5: PBU Work Flow

Finally, the Instruction for Bypass unit (I.B.) will be equals to the addition of $\mathrm{M}_{\mathrm{ax}} \mathrm{IRE}, \mathrm{M}_{\mathrm{in}} \mathrm{ING}$ and $\mathrm{AING}$; when $\mathrm{I}_{\mathrm{n}} \mathrm{M}_{\mathrm{ax}} \mathrm{D}$ will be greater than $\mathrm{M}_{\mathrm{ax}} \mathrm{IRE}$.

Now if $I_{n} M_{a x} D$ becomes equal to $M_{a x} I R E$, value of $\mathrm{M}_{\text {in }} \mathrm{ING}$ will be set as zero. Then, I.B. will be the addition of $\mathrm{M}_{\mathrm{ax}} \mathrm{IRE}$ and AING. If $\mathrm{I}_{\mathrm{n}} \mathrm{M}_{\mathrm{ax}} \mathrm{D}$ becomes less than $\mathrm{M}_{\mathrm{ax}} \mathrm{IRE}$, value of $\mathrm{M}_{\mathrm{in}}$ ING and AING both will be set as zero. Then, I.B. will be equals to only $\mathrm{M}_{\mathrm{ax}}$ IRE. 
When I.B. is assigned to PBU by ASC, PBU will work as I.B. until the defined interval not arrives. After a certain interval, it will receive next I.B. from ASC by following the steps before the interval time comes.

\section{Room/Other Usage Control Unit (RCU/XCU):}

RCU or XCU will be installed in SDB. ACS712 Hall effect type sensor will feed in the Voltage and current related value with the transient values. These values will be transmitted via NodeMCU V2 alike Wi-Fi module to ASC unit. When ASC needs to switch off the Circuit Breaker (C.B.) of the RCU, it will send instruction to the RCU microcontroller. RCU side microcontroller will command CB switcher to switch the C.B. on or off. In case of multiple C.B. installed on the SDB, there will be multiple $\mathrm{CB}$ switcher under one RCU microcontroller.

\section{Electrical Mapping for Load Behavior Analysis:}

Electrical Mapping Phenomena is introduced by ASC unit. It is shown in ASC Display and in every different load area display board or as user requires. It will analyze the XCU category and then its readings. It will also record from tripped action to power data entries. These data will be gathered in DS and will be manipulated for further use.

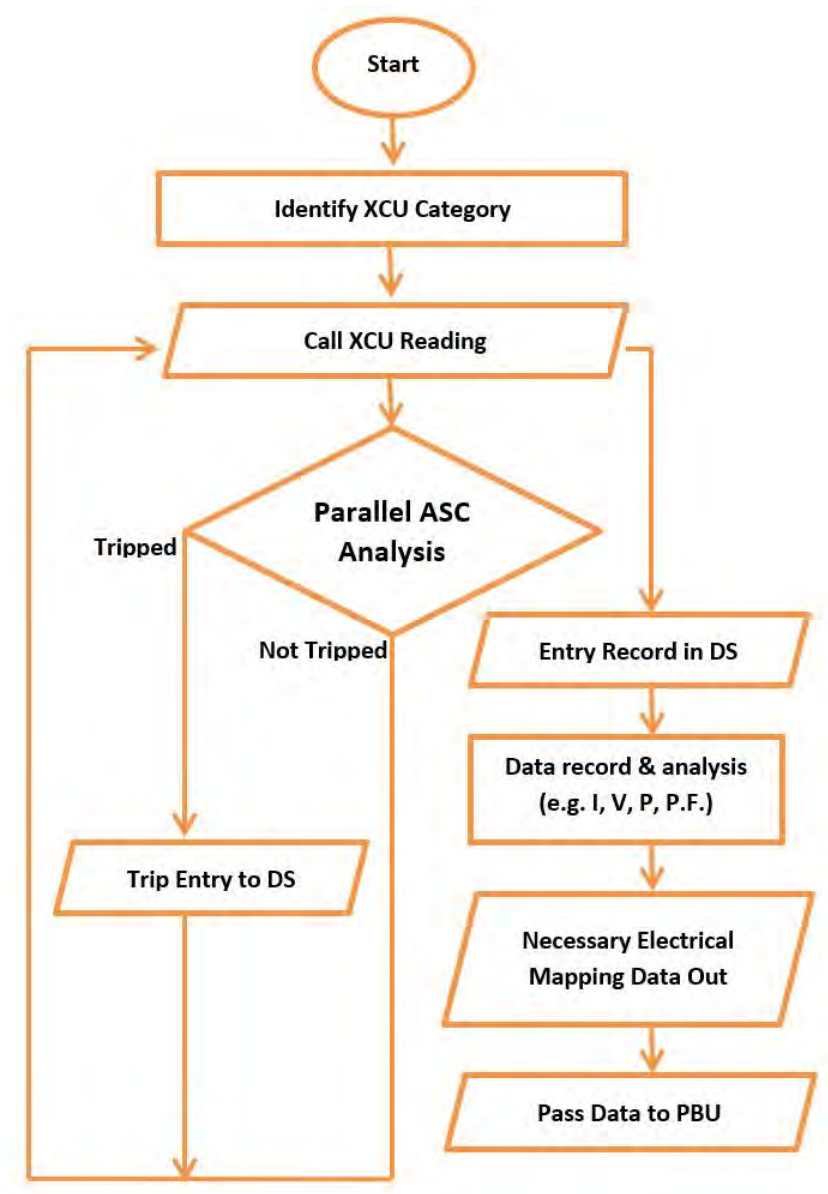

Fig. 6: Electrical Mapping Technique
Research for Data Logging with several phenomena which has been based on Microprocessor [24], Microcontroller [2526], IoT [27-30], PLC [31], Web based IoT [32], GSM Based IoT [33], can be some good approach for mapping. Data mining related work [34] is getting helpful to build load behavior analysis over time [35-36]. But here, Logging data by microcontroller wirelessly and creating a server alike web based Supervisory Control System makes the system quite handy and useful.

\section{E. ASC Activity:}

ASC of the Demand Side, is the brain of the system. It will instruct the other parts by taking the data from XCU and system itself. It will have an artificial intelligence type system but fully controlled by human being. That means, it won't be able to override user defined values but will try to balance the command on critical condition.

The main activities of ASC are -

- Instantaneous Tariff estimation and budget balance.

- Categorizing the load for emergency or observation.

- High Power Saving Mode based on load priority.

- Balancing Extra Power Facilities like - EV charging station, Laptop or Mobile charging station.

- Load behavior identifying by Electrical Mapping theory.

\section{Proposed Algorithm BASEd CALCUlations}

The research was done assuming an educational institute. The data will be represented as regional values and consumption based on specific weather and season for an experimental comparison.

\section{A. RPSU/XPSU Power Saving Observations:}

One Classroom named as "Classroom A" has been taken as reference, where five LEDs, one Air Condition unit, one multimedia device including one computer are taken on account. The working hour was $8 \mathrm{am}$ to $5 \mathrm{pm}$ on average where six classes period is accommodated, in total 9 hours a day. And working days was 26 days. The Tariff Category was (10 tk per unit) of Commercial Education Purpose. If 5 LEDs are rated $0.030 \mathrm{kWh}$ each, 1 A.C. rated $4 \mathrm{kWh}$, and other power demand is around $0.75 \mathrm{kWh}$ approximately. The Total Maximum Power Demand of this criteria becomes 5 $\mathrm{kWh}$. And, for the Cost of the month, came for the above data, is $11,700 \mathrm{tk}$.

Now, Applying Power Saving Mode, 10 minutes of power consumption on average from 6 classes time of a class room on a day, was saved on the next month. As a result, for power saving technique, the Cost of last experimental month appeared 10,400 tk.

That means 1,300 tk (11.11\% Cost) was saved on a single class room per month with that Power Saving Mode of XPSU. 
If we calculate for 30 classrooms in 8 active floors each, then the saving cost would reach to around 3,12,000 tk. So, We can say even with all the ASC units Power consumptions, it can save at least around $10 \%$ of electricity bill.

Moreover, it shows the reduction of 31.2 MW National Grid Pressure per month, for 8 floors which have 30 rooms each, for 1-hour reduction in 26 days as working days, where $5 \mathrm{kWh}$ is rated.

\section{B. PBU observations due to reduced power input from $N G$ :}

According to recent Renewable Energy Policy of Bangladesh, Maximum of $5 \mathrm{MWh}$ Generated Renewable Energy Power Plant can be deployed for tax free operation. On the above institutional case, we can see the per month usage of mentioned load scenario and for 30 rooms in each floor of a floor count of 8, where, $280 \mathrm{MW}$ power consumption per month is observed (1.2 MWh).

In case of $\mathrm{M}_{\mathrm{ax}} \mathrm{IRE}$ theory of PBU we can get $1170 \mathrm{MW}$ generation per month if $5 \mathrm{MWh}$ is generated by Renewable Energy Grid on Working times. But on that institute, only 50 $\mathrm{m}^{2}$ area can be afforded for PV Solar Cell based R.E. Grid. On commercial aspect, we can have around $6.25 \mathrm{KWh}$ Maximum on this situation. So, for the above monthly work time, 1.5 MW PV generation per month is possible for that institute.

So, 1.5 MW can be saved by Renewable Energy Grid and PBU assistance. Though it will be around $0.54 \%$ per month Power Saving from National Grid Usage. But it is around 15,000 tk per month savings from overall Electricity Bill.

On the other hand, the more the PV efficiency and PV installation area will increase the more the PBU will multiply the savings. This will always boost up the Savings.

\section{Power saving by $X C U$ :}

$\mathrm{XCU}$ does not involve in direct power saving, rather it performs action under critical situations for ASC instruction and respond user defined platforms. So, it is completely user and ASC dependent.

But from the analysis, for ASC switching event and other purpose XCU received some priority-based switching instruction from ASC. Taking the average value, leads to $0.5 \mathrm{MW}$ power saving per month. Here, $0.75 \mathrm{kWh}$ power multiplied by 3 floors of 15 rooms in each one. The switching event shows in total 2 hours on 8 days. It added $0.18 \%$ Power Savings for ASC Operation.

\section{Electrical Mapping benefit:}

For a perfect Electrical Mapping benefit we have to observe the load-site characteristics for a year. On the basis of algorithm, ASC tries to create a priority-based pressure on XCU to reach user defined month end cost limit. This priority information was taken from a institute of four months data.

ASC should analyze that some room has less use of multi-media. So, it will switched off all the multi-media facilities for that particular time by ASC User-defined
Priority Protocol (UPP); For event purpose, switching off the low priority loads, Auditorium should be powered up.

\section{MODEL REPRESENTATIONS}

The entire system was represented by MATLAB and Simulink. Some systems were represented by implementing prototype to visualize the Intranet Based Control plan.

\section{A. XPSU, XCU, PBU Based Observations:}

According to the algorithm and calculation, whole system was designed on Simulink. The power saving criteria was observed for the proposed XPSU, XCU, PBU algorithm. The IoT Based Operation was visualized on the later portion.

\section{1) Simulation Data:}

The Simulation was done for 1800 hours. The algorithm indicates Approximately $88.89 \%$ On-time Consumption that means $11.11 \%$ ASC Switching Event. Depending the ASC Switching Event Value, the Duty Cycle was generated to the system. According to the simulation; after $11.11 \%$ ASC Switching, the "Saved Power Information" data shows $31.91 \%$ power that has been Saved.

The "Saved Power" Scope output for the simulation results like the fig. 7. According to the graph, approximately (around $47 \mathrm{~kW}$ multiplied by 54 times) $2538 \mathrm{~kW}$ is saved, which is as same as the metered value shown on the simulation.

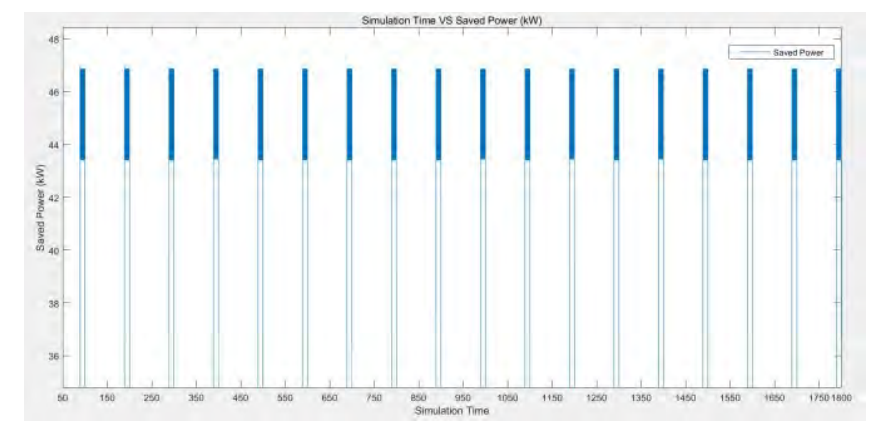

Fig. 7: Saved Power (Peak Value) for $11.11 \%$ ASC Switching

If ASC Switching is done less than $11.11 \%$, the "Saved Power Information" data shows less power saving percentage. For example, $1.15 \%$ ASC switching shows $2.954 \%$ Power Saving result. And, if $6.67 \%$ ASC Switching is done on the simulation, the "Saved Power Information" data shows 19.14\% Power Saving result.

The analysis shows that $11.11 \%$ ASC Switching is the highest average switching for the system. More than $11.11 \%$ can be achieved if the dynamic behavior of the load increases the Power Saving Adaptation on the system. To be cleared that ASC Switching can be done manually by categorizing the load on the SCADA system or Automatically by system behavior.

So, it will save power as the ASC switching event behaves. But to maintain a standard ASC Switching, the algorithm should be maintained and can be updated also. The ASC Switching and Power Saving related Data analysis has been explained on the next. 


\section{2) Data Analysis Based On Power Saving:}

As ASC Switching can be varied, simulation was done on the variation of ASC Switching also. It seems that the more the ASC switching is done, the more amount of power can be saved (fig. 8). In that case, curve equation behaves like a polynomial equation of four degrees.

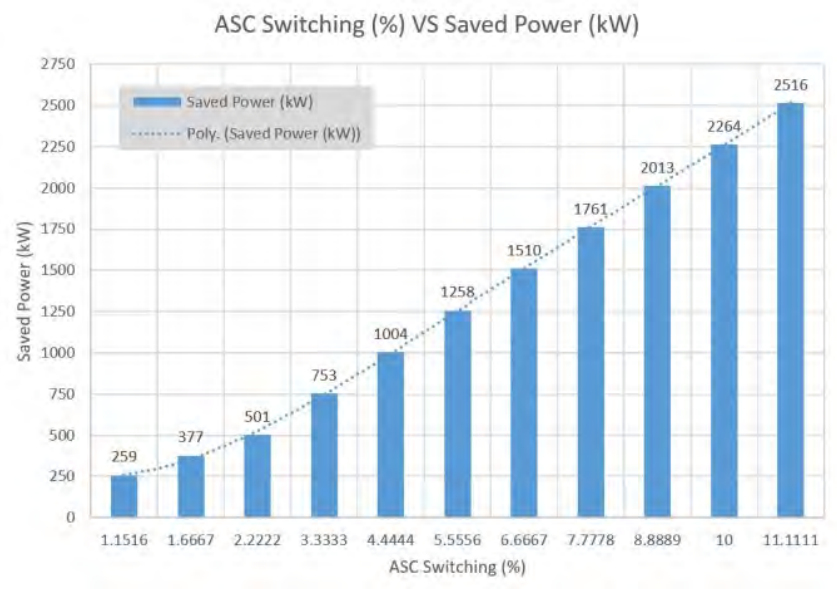

Fig. 8: ASC Duty Cycle (\%) VS Saved Power (kW)

According to the mentioned algorithm, 88.88\% Duty Cycle has been achieved, that means $11.11 \%$ ASC Switching is done. The less the ASC Switching is done, the less the Power will be saved. And for $11.11 \%$ ASC Switching, near about $31.91 \%$ Power has been Saved.

The graph (fig. 9) shows the point or curve for different Power consumption on different Pre and Post ASC Switching Period. Suppose, on a situation $7886 \mathrm{~kW}$ Power is supposed to be consumed in 1800 hours for a class room. If $6.67 \%$ ASC Switching is done according to the algorithmbased operation, then the Post ASC Switching result will be $6377 \mathrm{~kW}$ (Power Consumption). Here, around 20\% of Power Consumption has been Saved for that situation.

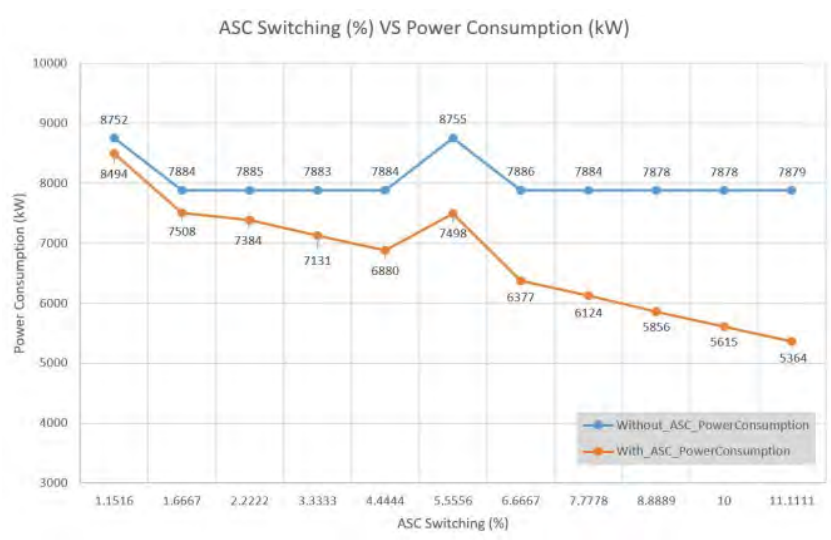

Fig. 9: ASC Duty Cycle (\%) VS Power Consumption (kW)

Not depending on the load, the increase in ASC Switching, shows the decrease in Power Consumption. That means, More Power will be saved if ASC is switching is increased which verifies the figure no. 8 also.

Now, we will see the monthly load curve analysis of one class room and other load. The Algorithm based ASC switching is done for the demand parameter. It is visible that gradually the system has been adapting the tendency to save more power than demand. But it could not save power from the important Demand criteria. For that reason, in some day, the saving percentage got reduced. But ultimately it rises to its ability.

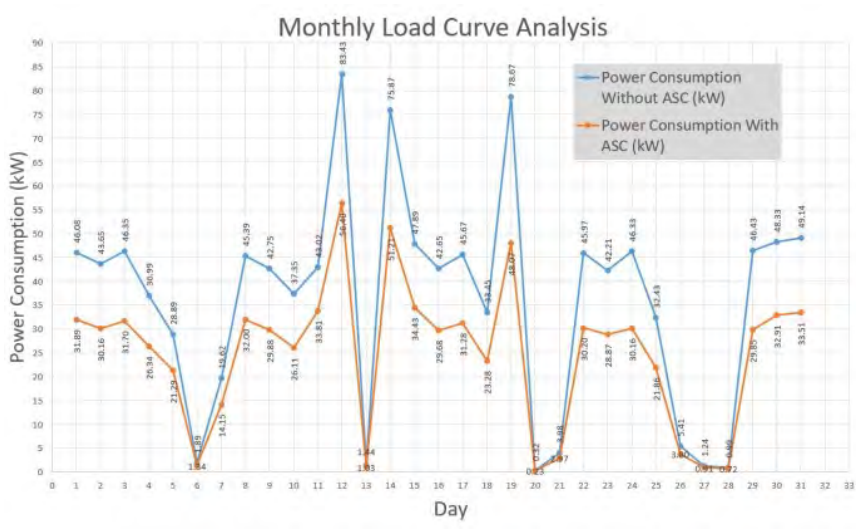

Fig. 10: Day-wise Power Consumption

From figure, it can be observed that, over $25 \mathrm{~kW}$ the power saving percentage is good. But for the load below $25 \mathrm{~kW}$ per day, the system has less effect of power saving strategy. Over $25 \mathrm{~kW}$, despite of having an ups and downs in saving percentage, an effect of gradual adaptation of power saving percentage increment has been seen on the analysis.

\section{B. A Part of XPSU Prototype Device:}

Several Devices can be included to XPSU Unit. According to the XPSU algorithm, every door should be under a device that takes care of the number of persons enter or leave and send the data to ASC.

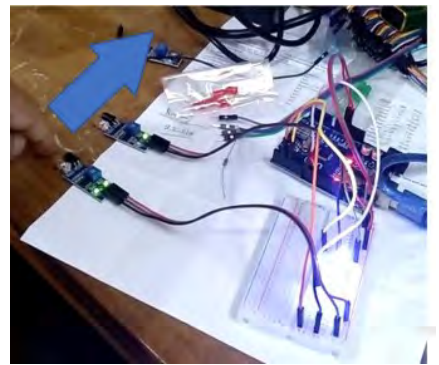

Fig. 11: One Sample XPSU Device (Sample: Automatic mode).

ASC will switch the load comparatively. A small prototype of this type of XPSU device is implemented to test the proposal. This prototype shows the automatic switching of the load for the presence or absence of incoming person. Two sensors were used for precision.

The algorithm and calculation done upon the XPSU model design. It is seen that around $11.11 \%$ ASC Switching is possible under normal circumstances. However, on further decision, it can achieve more. With the device above, an estimation of ASC Switching is done on a class room on class time ( $8 \mathrm{am}$ to $5 \mathrm{pm}$ ). The results are shown on the figure no. 12 .

From the data, $10.3 \%$ ASC Switching was done for XPSU instruction. But $10 \%$ was considered for simulation purpose. The XPSU controlling shows a high dynamic 
power saving result on the analysis of XCU Intranet Based Control Observation.

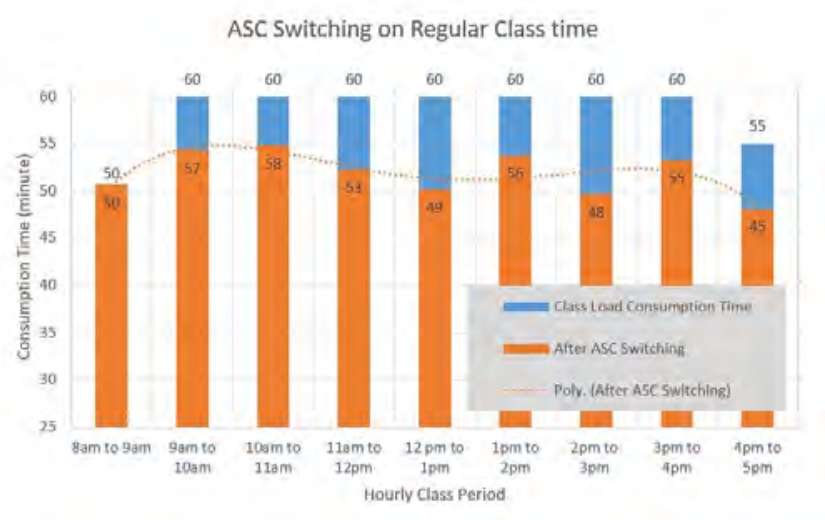

Fig. 12: ASC Switching via XPSU Device on Regular Class Time.

\section{1) Network Prototype:}

Importing the Power Line data from a portable device is a fact that should be logged accurately for ASC Analysis, Decisions and Actions. As proposed diagram (fig. 3), a prototype has been implemented to test the data feeding and some automatic action-based ASC Operation.

There was two ways to feed the data to the system. One is to use clamp-based hall sensor and the other is wire-based hall sensor. On the first method, accuracy is still under research to commercially implement. But on the second method, it is quite handy to feed the data accurately and hand over the rest duties to the microcontroller code.

For the second method, the connection process is to disconnect one line and install the necessary wired data feeder device in between the line. The feeder can be installed in between SDB and Load side.

With the prototype version, no additional switching device may not needed if the relay is used. Without relay, other advance Circuit Breaker Switcher can be implemented but it should be linked with the data feeder microcontroller. Here. ESP8266 (NodeMCU V2) is implemented as XCU's Data Feeder and Controller. By the help of 30 A tolerant ACS712 hall sensor, ESP8266 sent the data to the server as per instruction of code. It also receives control operation for the relay that is connected in between SDB and Load to control the Power Flow.

2) Intranet Data Acquisition and Control Test Result:

Portable Hotspot has been established to create an intranetbased web server. If the corresponded web address is entered on the hotspot connected computer's browser, the data representation can be visible.

Several control buttons can be linked to the system. Some action is done in automation according to some algorithm condition. The tested web server (fig. 13) was for one room. For several rooms, the design should be changed to visualize the Data in one screen.

\section{"ASC Based Power Measurement System For Demand Side Load"}

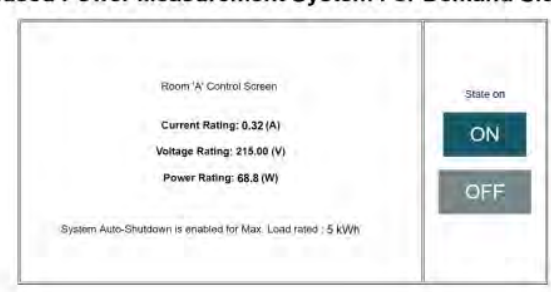

Fig. 16: Prototype of Data Feeder and Controller of XCU

Initially the server is tested for instantaneous automation and manual switching purpose. This webserver can also be designed for both instantaneous (automation or manual) action purpose and Data Logging (to storage) purpose simultaneously. For multiple room, this system will be changed to another dimension that is explained on fig. 1. RPSU, XCU, PBU will send the data to Raspberry Pi Model. Raspberry Pi will instruct them as per mentioned on the ASC algorithm.

\section{CONCLUSION}

The ASC-DSL plan shows the proper path for demand side load management for the future environment. This system secured around $31.9 \%$ power saving hope for $11.11 \%$ ASC switching. For demand side over $25 \mathrm{~kW}$ (per day), the advantage of power saving strategy of this system is applicable. From household to bigger institution, the plan will be stable. But, due to the lack of dynamic load behavior test environment in simulation, three phase industrial load and GWh ranged load has not yet been tested for this plan. Usually, 2 to $3 \mathrm{MWh}$ demand side can be under this ASCDSL plan without any hassle. This system also can be implementable easily for around 9 to $11 \mathrm{MWh}$, if $5 \mathrm{MWh}$ renewable energy grid can be affordable. Higher than the mentioned demand, will have to go through proper PBU analysis to avoid unbalanced system, PFI malfunction and phase related fault analysis. The adaptation tendency in power saving graph shows that it will gradually help the client to save the power which should not be needed to consume. And the client can pre-allocate the priority. IoT based data acquisition and supervisory control interface has been tested to make the ASC-DSL plan implementable. In the case of real-time control behavior, slight delay of milliseconds to 5 seconds can be seen. But it is not a big issue for this system. Constant VPN support will be needed for wide connectivity and high security. The electrical mapping theory is assigned to support the ASC decision and load behavior visualization. The XPSU, PBU and XCU behave like an assistant for ASC to switch the load and power inlet control. More ASC switching, increases the power saving percentage. For well-organized demand side load management and power saving plan, the ASC-DSL will create a powerful impact on the power system, smart grid operation and control sector.

\section{REFERENCES}

[1] Gopal H.G., N. A. Ranjan, M. S. Raviprakasha and K. A. Krishnamurthy, "Energy Audit and Demand Side Management Issues Applied to a Professional Engineering Institution," 2002 National Power Systems Conference, 2002, pp. 290-293. 
[2] M. M. Ahmed and W. L. Soo, "Customized SCADA system for low voltage distribution automation system," 2009 Transmission \& Distribution Conference \& Exposition: Asia and Pacific, Seoul, 2009, pp. 1-4.

[3] Figueiredo, João \& Sa da Costa, Jose. "A SCADA system for energy management in intelligent buildings," Energy and Buildings, 49, 2012, pp. 85-98.

[4] Liang Wang, Xiuting Wang, "Research on the SCADA system constructing methodology based on SOA," Procedia Engineering 29, 2012, pp. 3583-3588.

[5] D. Balsamo, D. Porcarelli, L. Benini and B. Davide, "A new noninvasive voltage measurement method for wireless analysis of electrical parameters and power quality," Sensors, 2013 IEEE, 2013, pp. 1-4.

[6] V. V. Kondalkar, Xiang Li, Ikmo Park, Sang Sik Yang and Keekeun Lee, "Development of chipless, wireless current sensor system based on giant magnetoimpedance magnetic sensor and surface acoustic wave transponder," Scientific Reports (2018), 2018, pp 1-11.

[7] F. Rahmatian and A. Ortega, "Applications of Optical Current and Voltage Sensors in High-Voltage Systems," 2006 IEEE/PES Transmission \& Distribution Conference and Exposition: Latin America, Caracas, 2006, pp. 1-4.

[8] Shitharth S. and Prince Winston D., "An enhanced optimization based algorithm for intrusion detection in SCADA network", Computers \& Security, Vol. 70, 2017, pp. 16-26.

[9] Khorram M., Faria P., Abrishambaf O, and Vale Z., "Demand Response Implementation in an Optimization Based SCADA Model Under Real-Time Pricing Schemes," Rodríguez S. et al. (eds) Distributed Computing and Artificial Intelligence, Special Sessions, 15th International Conference. DCAI 2018. Advances in Intelligent Systems and Computing, vol 801. Springer, 2019, pp. 21-29.

[10] S. P. Anjana and T. S. Angel, "Intelligent demand side management for residential users in a smart micro-grid," 2017 International Conference on Technological Advancements in Power and Energy, Kollam, 2017, pp. 1-5

[11] Ming-Yuan Cho, Jung-chin Chen. "A SCADA System Application in Load Management," Proceedings of the Fifth International Conference on Electronic Business, Hong Kong, December 5-9, 2005 , pp. $725-728$

[12] Marco Pasetti, Stefano Rinaldi and Daniele Manerba, "A Virtual Power Plant Architecture for the Demand-Side Management of Smart Prosumers", Appl. Sci. 2018, 8, 432, pp. 1-20.

[13] S. Paramasivam, L. Thillainathan, H. Zeynal, N. Diana, "CostEffective and Real-Time SCADA Home Energy Monitoring System", 2014 IEEE 8th International Power Engineering and Optimization Conference (PEOCO2014), Langkawi, The Jewel of Kedah, Malaysia. 24-25 March 2014, pp. 585-590.

[14] Aye Min Zaw, Hla Myo Tun, "Design and Implementation of SCADA System Based Power Distribution for Primary Substation ( Monitoring System)", International Journal of Science, Engineering and Technology Research (IJSETR), Volume 3, Issue 5, May 2014, pp. $1542-1546$.

[15] Mukesh Kumar, Sanjeev Sharma and Mansav Joshi, "Design of Real Time Data Acquisition with Multi Node Embedded Systems", International Journal of Computer Applications (0975 - 8887), Volume 42- No.11, March 2012, pp. 6-12

[16] Bindu Pillai, Vishal Mehta, Nilam Patel, "Development of Supervisory Control and Data Acquisition system for Laboratory Based Mini Thermal Power Plant using LabVIEW", International Journal of Emerging Technology and Advanced Engineering, ISSN 2250-2459, Volume 2, Issue 5, May 2012, pp. 449-453.

[17] S.M. Zia Ul Azim, Md. Mohiuddin Uzzal, Ahmed Mortuza Saleque and Md. Abdur Rahman, "Feasibility Study of Off-Grid Sustainable Energy System for Coastal Bhasan Char to Rehabilitate Rohinga Refugees" Aiub Journal of Science and Engineering (AJSE) Vol:17, Issue:3, pp. 85-92
[18] Rabeea Hasan, Junaid A. Qureshi, M. Safwan Khan, Youmna Tanveer, Alvia Abbas, Waqar A. Qureshi, M. Mohsin Aman, "Smart Electricity Demand Side Controller," 3rd IET International Conference on Clean Energy and Technology (CEAT) 2014 Kuching, 2014, pp. 1-6.

[19] Saulo, M.J. and Omondi, V.O., "Design and Analysis of Solar Energy Mini-Grid for Rural Electrification,” Open Access Library Journal, 2: e1903, 2015, pp. 1-10.

[20] Zvonimir Klaić, Krešimir Fekete, Damir Šljivac, "Demand side load management in the distribution system with photovoltaic generation", Tehnički vjesnik 22, 4(2015), pp. 989-995.

[21] Park, L., Jang, Y., Cho, S., Kim, J.: Residential demand response for renewable energy resources in smart grid systems. IEEE Trans. Industr. Inf. 13(6), 2017, pp. 3165-3173.

[22] Gazafroudi, A., Pinto, T., Prieto-Castrillo, F., Corchado, J., Abrishambaf, O., Jozi, A., Vale, Z.: Energy flexibility assessment of a multi agent-based smart home energy system. In: IEEE 17th International Conference On Ubiquitous Wireless Broadband (ICUWB), Salamanca, Spain, 2017, pp. 1-7.

[23] Leo Raju, Sajna G., Prithika rani M, "IoT Based Advanced Energy Management of Micro-grid" International Journal of Pure and Applied Mathematics, Volume 120 No. 6 2018, pp. 1443-1452.

[24] Robert R. Dedrick, John D. Halfman and D. Brooks McKinney, "An Inexpensive, Microprocessor-Based, Data Logging System", Computers \& Geosciences - COMPUT GEOSCI. 26. 1059-1066. 10.1016/S0098-3004(00)00020-0, 2000, pp. 1-15.

[25] Ishaan Dua, Prerna Choudhary, Shubham Soni and Sheila Mahapatra, "Microcontroller Based Data Acquisition And Supervision", International Journal of Scientific \& Technology Research, Volume 4, Issue 05, May 2015, pp. 95-99.

[26] Raghda Bakerey Khader Elssadig and Eltahir Mohammed Hussien, "Microcontroller Based Data Logger", International Journal of Engineering, Applied and Management Sciences Paradigms, Vol. 42, Issue 01 , pp. 70-73

[27] Khalid A. Fakeeh, “An IoT based Smart Power Management System for Technical University", International Journal of Computer Applications (0975 - 8887), Volume 149 - No.1, September 2016, pp. 39-45.

[28] Minoli, D., Sohraby, K., Occhiogrosso, B.: IoT considerations, requirements, and architectures for smart buildings - energy optimization and next generation building management systems. IEEE Internet Things J. 4(1), 2017, pp. 269-283.

[29] Giampaolo Fiorentino and Antonello Corsi, "Internet of Things for Demand Side Management", Journal of Energy and Power Engineering 9, 2015, pp. 500-503

[30] Madhuri G. Hiremath, Veeresh Pujari, Baswaraj Gadgay, "IOT Based Energy Monitoring and Control Device", International Journal for Research in Applied Science \& Engineering Technology (IJRASET), Volume 5 Issue VI, June 2017, pp. 711-715.

[31] Kaushik Bhuiya, Kintali Anish, Dhwani Parekh, and Kilaru Laxm Sahiti, "Low cost wireless control and monitoring using PLC and SCADA", International Journal of Scientific and Research Publications, Volume 3, Issue 9, September 2013, pp. 1-4

[32] NY Dahlan, AAM Aris, MA Saidin, MJM Nadzeri, MNM Nawi, WF Abas, AF Abidin, $\mathrm{H}$ Mohammad, $\mathrm{Z}$ Zakaria1, $\mathrm{P}$ Arshad, "Development of Web-Based Real-time Energy Monitoring System for Campus University", Journal of Telecommunication, Electronic and Computer Engineering, ISSN: 2180-1843 e-ISSN: 2289-8131 Vol. 8 No. 10, pp. 157-164

[33] Mahmoud Shaker Nasr, Ali Najim Abdullah, "Design and Implementation of IoT Cloud Moveable SCADA Supported by GSM for Industrial Applications", Journal of Babylon University/Engineering Sciences/ No.(2)/ Vol.(25): 2017, pp. 409424.

[34] Maria Muntean, Ioan Ileana, Corina Rotar, Mircea Risteiu, "Data Mining Learning Models and Algorithms on a Scada System Data 
Repository", BRAIN. Broad Research in Artificial Intelligence and Neuroscience, ISSN 2067-3957, Volume 1, July 2010, pp. 91-99.

[35] Chaitanya Kulkarni, Indrajit Rananavare, Shubham Patil, Niket Ther, Pratik Chavan, Faija Magdum, Suraj Ghatage, Bharat Kulkarni, "Power monitoring with time controlling \& data logging", International Research Journal of Engineering and Technology (IRJET), Volume: 06, Issue: 04, April 2019, pp. 336-339.

[36] Lawrence Oriaghe Aghenta and Mohammad Tariq Iqbal, "Low-Cost, Open Source IoT-Based SCADA System Design Using Thinger.IO and ESP32 Thing", Electronics 2019, 8, 822, pp. 1-24.

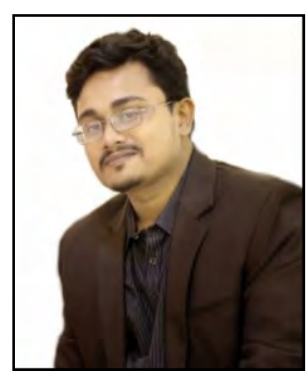

Meer Shadman Shafkat Tanjim received Bachelor of Science in EEE from American International University-Bangladesh (AIUB). His Master Degree is also from AIUB in EEE Background. He started his profession at Bangladesh Institute of Science \& Technology (BIST) as Lecturer in the Dept. of ECE on May 2017. On around November 2017, he switched to European University of Bangladesh (EUB) in the Dept. of EEE. His involvement in Music made him experienced of an era. His passion both in Music and Teaching, creates an example among. Recently, he is researching on Control System Strategies, Solar \& Wind Energy, Robotics, Aeronautics, Smart System and IoT aspects.

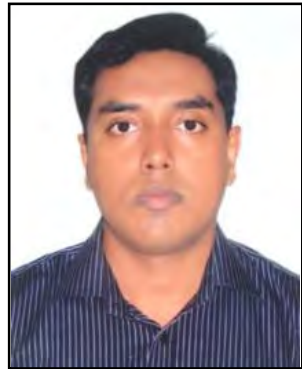

Md. Abdur Rahman received his $\mathrm{PhD}$ in wireless communications from Tokyo Institute of Technology, Japan in 2013. He received BSc Engg. and M.E. degrees from American International University Bangladesh (AIUB) and Asian Institute of Technology (AIT), Thailand, respectively. He joined AIUB as a lecturer in 2002, and currently employed as Professor and Associate Dean of the Faculty of Engineering in the same university. His recent research interests include cognitive radio, bioinformatics, wireless systems, ICT etc. At present, he is conducting postdoctoral research in the School of Engg. and IT at Federation University Australia. He is a Life member of IEB and senior member of IEEE. During his doctoral studies, he led a team of students formed by both undergraduate and postgraduate students for designing an emergency wireless network. The team took part in four international research competitions and won four prizes.

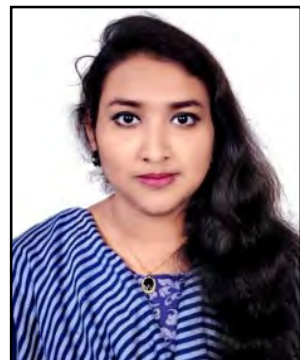

Ashrafun Nushra Oishi received Bachelor of Science (B.Sc.) in EEE from American International University-Bangladesh (AIUB). Her Master Degree is also from AIUB from MEEE Department. She started her career on May 2018 at European University of Bangladesh (EUB) as Lecturer in the Dept. of EEE. Her research interest is focused on Solar Cell, Renewable Energy, Robotics and Control Systems. 